\title{
Tool wear by dissolution during machining of alloy 718 and Waspaloy: a comparative study using diffusion couples
}

\author{
Philipp Hoier $^{1}$ (1) $\cdot$ Kumar Babu Surreddi $^{2,3} \cdot$ Uta Klement $^{1}$
}

Received: 4 July 2019 / Accepted: 6 December 2019 / Published online: 17 December 2019

(C) The Author(s) 2019

\begin{abstract}
The wear of metal cutting tools is known to take place by the combined and simultaneous effects of several wear mechanisms. Knowledge of the relative contribution of the individual wear mechanisms is required to understand and predict the tool wear during cutting different workpiece materials and alloys. It has been shown previously that machining two heat resistant superalloys, alloy 718 and Waspaloy, leads to distinctively different tool wears. Even though the subject has been addressed in various studies, there are still open questions regarding the underlying reasons for the differing tool wear rates. In particular, the relative contributions of diffusion/dissolution when machining the two alloys have not been addressed so far. Therefore, a qualitative comparison of the chemical interaction between the tool material and the two superalloys was made by using diffusion couple tests. The aim was to mimic the high temperatures and intimate contact between workpiece and tool material at the tool rake and flank faces during cutting under controlled and static conditions. The obtained results suggest that it is unlikely that differences in flank wear rate when machining the two superalloys are caused by significantly varying magnitudes of tool atoms dissolving into the respective workpiece. Analysis of the tool/superalloy interfaces in the diffusion couples revealed diffusion-affected zones of similar size for both tested superalloys. Increasing test temperature led to enhanced interdiffusion which suggests an increase in tool wear by diffusion/dissolution for higher cutting temperature. For alloy 718 , the higher test temperature also led to depletion of carbon together with formation of tungsten within the tool in close vicinity to the interface with the superalloy.
\end{abstract}

Keywords Metal cutting $\cdot$ Tool wear $\cdot$ Dissolution $\cdot$ Diffusion $\cdot$ Waspaloy $\cdot$ Alloy 718

\section{Introduction}

Due to its significant impact on many process characteristics, the understanding and prediction of tool wear in metal cutting have drawn considerable attention [1-5]. The negative impact of tool wear on the surface properties of machined components necessitates a timely change of a cutting tool before a critical level of wear has been reached [6]. This is of particular relevance for safety critical applications, like aircraft engine components where high-temperature materials like superalloys are used. Machining of this type of material results in

Philipp Hoier

hoierp@chalmers.se

1 Department of Industrial and Materials Science, Chalmers University of Technology, SE-412 96 Gothenburg, Sweden

2 Materials Engineering, Lund University, SE-221 00 Lund, Sweden

3 Materials Technology, Dalarna University, SE-791 88 Falun, Sweden rapid tool wear which is why superalloys are considered a difficult-to-machine material [7].

Advanced coatings are generally used to provide cutting tools with improved wear resistance and longer tool life [8] especially in the case of machining difficult-to-cut materials [9]. However, despite the use of tool coatings, wear of the underlying tool substrate (most commonly cemented carbide) can become the tool life limiting factor since progressing tool wear can result in local loss of the applied tool coatings which in turn exposes the underlying tool substrate. Apart from the influence of coatings on the tool wear, the workpiece characteristics have also shown to affect the tool life significantly. For example, the tool wear behavior when machining superalloys using uncoated cemented carbide inserts can vary depending on the machined workpiece alloy, its properties, and microstructural characteristics [10-13]. Olovsjö and Nyborg [13] have compared the wear behavior of uncoated cemented carbide tools when machining two different superalloys, alloy 718 and Waspaloy. The superalloys in their study were tested after different heat treatments which were employed to 
achieve controlled microstructures with varying grain sizes. In that way, the influence of workpiece grain size on flank and notch wear was investigated for both superalloys. According to Olovsjö and Nyborg [13], the grain size mainly affected the tool notch wear when machining the respective superalloy workpieces. Furthermore, no effect of workpiece grain size on the flank wear was observed for both alloys [13]. However, the flank wear was significantly different when comparing the two superalloys. Irrespective of the grain size, significantly higher rates of flank wear development were observed for machining alloy 718 as compared with machining Waspaloy [13]. Similar observations were later reported by Polvorosa et al. [14] who employed conventional and highpressure cooling when machining the two superalloys with uncoated cemented carbide inserts. Even though the studies by Olovsjö and Nyborg [13] as well as by Polvorosa et al. [14] provided new insights into the influence of workpiece grain size and coolant supply pressure on the resulting tool wear response, the reasons behind the intrinsic difference between flank wear when machining both superalloys were not addressed in detail. Olovsjö and Nyborg [13] regarded the formation of oxides with beneficial tribological properties on the tool surfaces which exclusively form when machining Waspaloy as a possible reason for the lower flank wear when machining this alloy.

The subject was taken up again by Hoier et al. [15] who linked the different flank wear behaviors when machining alloy 718 and Waspaloy to varying amounts of hard, abrasive carbides present in both machined workpieces. The dominant active tool wear mechanism was identified to be abrasion [15]. However, tool wear is considered to be caused by several mechanisms which act simultaneously [16]. Even though one mechanism might be dominant under certain cutting conditions, other mechanisms can also contribute to the overall tool wear. Apart from abrasion, adhesion, and plastic deformation, tool wear by diffusion or dissolution process is another commonly reported active wear mechanism during cutting of various metallic workpiece materials [17-20] including superalloys [7, 21].

During metal cutting, high temperatures and intimate contact between the chip/workpiece and the cutting tool arise at the tool rake and flank faces, respectively. These conditions have shown to promote the transport of atoms across the interface between the tool and workpiece material by diffusion or dissolution mechanisms. One possible scenario is that the compounds of the tool material dissociate which is followed by atomic dissolution into the fast moving chip/workpiece which leads to direct loss of tool material [2, 3, 22]. Additionally, it has been reported that atoms of the workpiece material can diffuse into the tool material and lead to reactions with the tool material. An example is machining of titanium alloys. The wear of uncoated cemented carbide inserts is said to be accompanied by formation of titanium-rich carbides at the tool-workpiece interface [23-25] and/or carbon depletion and formation of pure tungsten [23].

The fact that the wear mechanisms act simultaneously makes it difficult to independently investigate the contribution of a certain mechanism. One possible way to assess wear by dissolution/diffusion separate from other mechanisms like abrasion or adhesion is the use of static diffusion couples. Diffusion couple tests aim at simulating the chemical interaction between tool and workpiece material in the cutting zone under controlled conditions [26]. In that way the relative contribution of diffusion/dissolution on tool wear can be compared for identical conditions excluding the effect of other process parameters such as the cutting fluid. Even though the dynamic situation at the tool/workpiece interface in the cutting zone is different from the static situation during diffusion couple tests $[19,26]$, it can still give qualitative information about the contribution of this wear mechanism when machining different alloys or using different tool materials. Regarding the uncoated cemented carbide tools, previous studies employing diffusion couple tests have primarily focused on machining of titanium alloys [23, 25, 27, 28] while diffusion couple studies on cemented carbide tools and superalloys have only rarely been reported [29].

This is partly the reason why despite several studies reporting on the tool wear responses during machining Waspaloy and alloy 718 [13-15], some open questions remain regarding the reasons for the intrinsically different tool wear rates. In particular, the contribution of diffusion or dissolution to the significantly varying tool wear for cutting the respective alloy has not been addressed so far. Such knowledge of the relative contribution of individual mechanisms to the overall tool wear can however be valuable input for more comprehensive wear prediction approaches which take the actual physical nature of the tool wear into account $[3,4,30]$.

The present study deals therefore with the assessment of tool wear by diffusion or dissolution during machining alloy 718 and Waspaloy with uncoated cemented tungsten carbide tools by means of static diffusion couple tests. The diffusion interfaces between the two superalloys and the tool material are qualitatively compared primarily by scanning electron microscopy and associated techniques. Furthermore, complementary to the static diffusion couple tests, a cross section of a worn tool used for cutting alloy 718 was examined. Observations and their implications are discussed with respect to the dynamic situation in the cutting zone when machining the two superalloys.

\section{Experimental}

Chemical interaction between the tool and workpiece in the cutting zone during machining was simulated by static diffusion couples. The tool material investigated was cemented 
tungsten carbide (Grade H13A, Sandvik Coromant). The average $\mathrm{WC}$ grain size and Co-content of the chosen grade are around $0.80 \mu \mathrm{m}$ and $10 \mathrm{vol} \%$, respectively.

Two different superalloys were chosen as the workpiece materials, alloy 718 (Ni-Fe-based) and Waspaloy (Ni-based). Their nominal chemical compositions can be seen in Table 1 .

For each experiment, one diffusion couple comprising one of the two superalloys and a sample of the tool material was tested under controlled conditions. Tool and superalloy were brought in contact so that the mating surfaces were squareshaped with $7 \mathrm{~mm}$ side length. Furthermore, to achieve good contact during the tests, the contact surfaces were ground and polished with $1 \mu \mathrm{m}$ diamond suspension as the final step. In that way, a total of four samples were prepared (two for each superalloy) and tested in accordance with Table 2. For each test, the sample was held together by applying a force of $1200 \mathrm{~N}$ corresponding to a pressure of $\sim 24.5 \mathrm{MPa}$ in compression for $90 \mathrm{~min}$ at two test temperatures. Flowing nitrogen was used as protective gas to prevent oxidation of the samples during the tests. A schematic of the experimental setup can be seen in Fig. 1a.

In order to assess the chemical interaction between the tool and workpiece, the diffusion couples were cross-sectioned. Metallographic sample preparation was carried out with 1 $\mu \mathrm{m}$ diamond suspension as the final polishing step.

The tool-workpiece interfaces were analyzed by using a LEO 1550 Gemini scanning electron microscope (SEM) equipped with a system for energy dispersive X-ray spectroscopy (EDS, Oxford X-Max silicon drift detector) and a system for electron backscatter diffraction (EBSD, Oxford Nordlys II detector). To analyze the distribution of elements, at least 5 EDS line scans across the tool-workpiece interfaces were acquired for each diffusion couple to ensure repeatability of the obtained results. Both imaging and EDS analysis was conducted at numerous locations spread across the diffusion interfaces in order to ensure the validity of the observations.

Furthermore, complementary analysis was performed with Auger electron spectroscopy (AES) using a PHI $700 \mathrm{Xi}$ Scanning Auger Nanoprobe with an acceleration voltage of $10 \mathrm{keV}$ and a beam current of $10 \mathrm{nA}$ for the diffusion couples tested at $1000{ }^{\circ} \mathrm{C}$. The data analysis software PHI MultipakTM was used for peak identification and data analysis. Sputtering was performed with $4 \mathrm{keV} \mathrm{Ar}^{+}$ion sputtering for $30 \mathrm{~s}$ to reduce the surface contamination.

Table 1 Chemical composition of investigated superalloys in wt $\%$ with $\mathrm{Ni}$ as balance

\begin{tabular}{lllllllll}
\hline & $\mathrm{Cr}$ & $\mathrm{Co}$ & $\mathrm{Mo}$ & $\mathrm{Nb}$ & $\mathrm{Fe}$ & $\mathrm{Al}$ & $\mathrm{Ti}$ & $\mathrm{C}$ \\
\hline Alloy 718 & 18.4 & - & 3.0 & 5.5 & 17.5 & 0.6 & 0.9 & 0.04 \\
Waspaloy & 19.4 & 13.2 & 4.1 & - & 1.2 & 1.3 & 3.1 & 0.03 \\
\hline
\end{tabular}

Complementary to the diffusion couple tests, a worn cutting tool used for turning alloy 718 was examined in cross section. The uncoated cemented tungsten carbide insert was used for face turning a workpiece of age-hardened alloy 718 [15], see Table 3. During the test, a cutting fluid (6-7\% emulsion) was supplied to the tool rake face. The cross section was prepared using conventional metallographic techniques using a colloidal silica suspension $(0.04 \mu \mathrm{m}$ particle size $)$ during the final polishing step.

\section{Results}

\subsection{Characterization of diffusion couples}

After testing for the set time and subsequent cooling to room temperature, the contact pressure was released from the samples. It was found that firm bonding between the tool material and the corresponding superalloy samples had occurred in all cases except for Waspaloy tested at $1000{ }^{\circ} \mathrm{C}$. Here the vast majority of the tool material had broken off. It is believed that during cooling down, differences between the thermal expansion coefficients of the tool material and the respective superalloys lead to build-up of stresses which resulted in the debonding. However, closer examination by optical microscopy and SEM revealed that pieces of tool material were left adherent to the Waspaloy surface in contact with the tool during the test (Fig. $1 \mathrm{~b}$ and c). Therefore, bonding had occurred during the test.

In Fig. 2, the general appearances of the bonded workpiece-tool interfaces are presented for the four tests. When looking at the interface after exposure to $800^{\circ} \mathrm{C}$, see Fig. 2a and c, no obvious microstructural changes of either the superalloy or of the tool are visible close to the interface. The WC skeleton (bright) is clearly distinguishable. The holes appearing in-between the WC skeleton are areas of the Cobinder, subjected to preferential removal during metallographic sample preparation.

After the tests at $1000^{\circ} \mathrm{C}$ however (Fig. $2 \mathrm{~b}$ and d), the WCCo microstructure within the area of about $3.5 \mu \mathrm{m}$ from the interface appears to have changed. Both the WC skeleton and Co-binder are not clearly distinguishable any more. Instead, there are zones of slightly darker contrast in-between the bright appearing WC grains. Furthermore, it can be observed that a band has formed consisting of interrupted bright areas in very close proximity to the diffusion interfaces of the alloy 718 sample tested at $1000^{\circ} \mathrm{C}$ (Fig. 2b). The band is approximately 0.5 to $1 \mu \mathrm{m}$ thick and stretches all along the investigated interface.

For qualitative comparison of interdiffusion between the materials, at least five EDS line scans were taken across each tool-workpiece interface. Three of these line scans from each sample are presented in Fig. 3. Shown are the normalized 
Table 2 Overview of the static diffusion couple tests

\begin{tabular}{lllll}
\hline Workpiece material & Tool material & Temperature $\left({ }^{\circ} \mathrm{C}\right)$ & Holding time $(\mathrm{min})$ & Contact pressure $(\mathrm{MPa})$ \\
\hline Alloy 718 & WC-Co & 800 & 90 & $\sim 24.5$ \\
Alloy 718 & WC-Co & 1000 & 90 & $\sim 24.5$ \\
Waspaloy & WC-Co & 800 & 90 & $\sim 24.5$ \\
Waspaloy & WC-Co & 1000 & 90 & $\sim 24.5$ \\
\hline
\end{tabular}

signal intensities of nickel and tungsten across the diffusion couple interfaces after the tests. In all graphs, a steep decrease or increase of X-rays originating from tungsten and nickel, respectively, can be seen in close vicinity of the toolsuperalloy interface (the interface is approximately at the center of the $x$-axis). When comparing the line scans corresponding to the tests at $800^{\circ} \mathrm{C}$ with the ones obtained after $1000^{\circ} \mathrm{C}$, a clear difference can be observed. The higher test temperature yielded in a more shallow increase and decay of tungsten and nickel, respectively. This can be connected to increased interdiffusion between the tool and superalloys which increased the respective element's X-ray signals within about $0.5 \mu \mathrm{m}$ distance from the interface. This is the case for both the alloy 718 and the Waspaloy containing sample and no significant differences can be observed between the two alloys. Furthermore and as can be seen in Fig. $3 a$ and b, it should be noted that the EDS line scans of the alloy 718 diffusion couple tested at $1000{ }^{\circ} \mathrm{C}$ show no significant change in the $\mathrm{X}$ ray intensities at the location of the bright phase.

Complementary to EDS, additional analysis by means of AES was carried out for the samples tested at $1000{ }^{\circ} \mathrm{C}$. As compared with EDS, AES offers higher spatial resolution and higher sensitivity on the orders of $10 \mathrm{~nm}$ and 0.1 at.\%, respectively [31]. Figure 4 shows derivatives of AES survey spectra obtained for the diffusion couple which contains alloy 718 . Characteristic Auger peaks are marked with the corresponding elements. Spectrum 1 shows presence of nickel, iron, and chromium in the tool, confirming diffusion of elements from the superalloy into the tool. At further distance from the interface (spectra 2 and 3), no elements from the superalloy were detected, which can be seen by the absence of the corresponding peaks in the AES spectra. Spectrum 4 was obtained on the bright phase formed in close vicinity to the diffusion interface (see also Fig. 2b). As can be seen, solely tungsten, carbon, and oxygen are present in the spectrum. The presence of oxygen in all spectra is likely to be the result of air which was entrapped between the mating sample surfaces. Even though these surfaces were polished for improved contact during the tests, remaining small-scale surface roughness can lead to small gaps between the mating surfaces. The entrapped air then caused diffusion of oxygen into the diffusion couples and can explain the oxygen peaks in the shown spectra. Similar to the alloy 718 sample tested at $1000{ }^{\circ} \mathrm{C}$, diffusion of elements of the superalloy into a narrow region of the tool adjacent to the diffusion interface was also confirmed for the corresponding Waspaloy sample.

Results of detailed analysis of the bright phase formed in the diffusion couple containing alloy 718 which was tested at $1000{ }^{\circ} \mathrm{C}$ are shown in Fig. 5. AES peak intensities of tungsten and carbon across the bright phase are shown in Fig. 5a. The relative peak intensities are a measure of the relative concentration of the respective elements at the locations. As compared with WC (left side of graph), the bright phase is depleted in carbon, shown by the low intensity of the corresponding peak at this position. The bright phase was found to be mainly tungsten. This was done by identifying candidate compounds from the carbon-deficient part of the tungsten-carbon binary phase diagram (Fig. 5b) followed by analysis of EBSD (a)

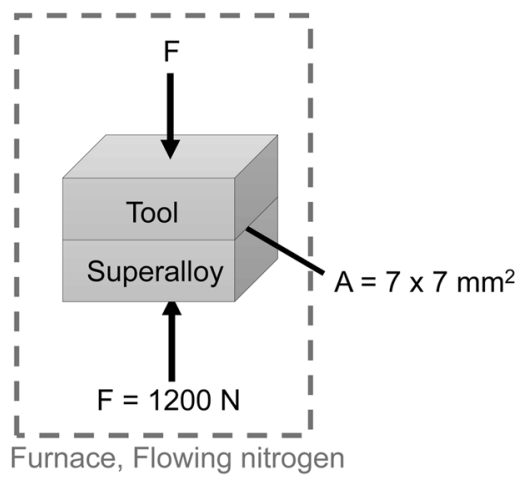

Fig. 1 Schematic setup of the diffusion couple tests with contact surface ("A") and applied force ("F") indicated (a); separated diffusion couple of Waspaloy after testing at $1000{ }^{\circ} \mathrm{C}$ shown in top-view (b), and tilted view (b)

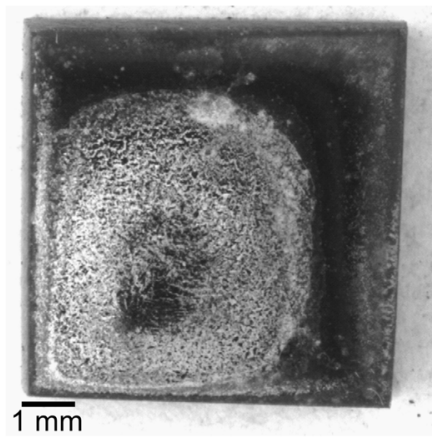

(c)

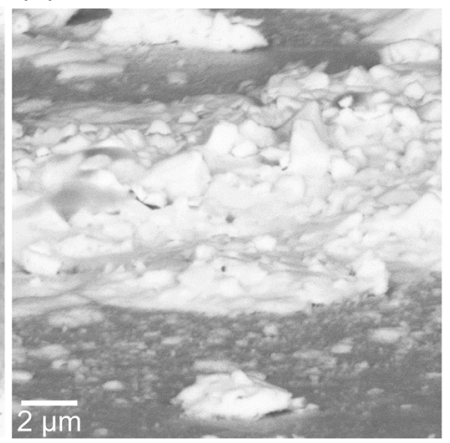

using SEM (c). Locally, several micrometer thick layers of tool material (bright particles are WC) are bonded to the Waspaloy sample 
Table 3 Tool characteristics, tool holder, resulting angles, and cutting parameters during turning tests [15]

\begin{tabular}{ll}
\hline Insert, ISO code & TCMW 16 T3 04 \\
Insert, grade & H13A (Sandvik, uncoated cemented carbide) \\
Tool holder & C3-STGCR-22040-16 \\
Tool rake angle $\left(^{\circ}\right)$ & 0 \\
Tool clearance angle $\left(^{\circ}\right)$ & 7 \\
Tool entrance angle $\left(^{\circ}\right)$ & 91 \\
Cutting speed & $45 \mathrm{~m} / \mathrm{min}$ \\
Feed rate & $0.1 \mathrm{~mm} / \mathrm{rev}$ \\
Depth of cut & $1 \mathrm{~mm}$ \\
Machining time & $5.45 \mathrm{~min}$ \\
Number of tests & 2 \\
\hline
\end{tabular}

patterns acquired on the bright phase (Fig. 5c). Figure 5d shows the match of the EBSD pattern of the bright phase with the reference pattern of tungsten. The bright phase also contains some carbon, which could be explained by the fact that small amounts of WC remain within the bright zones which were not resolved by the EBSD analysis.

Furthermore, niobium-rich phases were found to form in alloy 718 in close proximity to the diffusion interface (see Fig. 6). The shown appearance is characteristic for the entire length of the diffusion interface for the alloy 718 diffusion couple tested at $1000{ }^{\circ} \mathrm{C}$.

\subsection{Tool wear characterization}

Figure 7a provides a SEM micrograph showing the worn tool surfaces after turning alloy 718 . Additional micrographs in
Fig. $7 \mathrm{~b}$ and $\mathrm{c}$ show the subsurface of the worn tool on the rake and flank face, respectively. In both micrographs, adhered layers of workpiece material can be seen covering the worn tool surface. When comparing the WC-Co microstructure beneath the worn tool surfaces on both the rake (Fig. 7b) and flank face (Fig. 7c), no signs of microstructural changes similar to the one observed for the static diffusion couple tested at $1000{ }^{\circ} \mathrm{C}$ can be observed. In contrast to the static diffusion couple (Fig. 2b), the individual WC grains are still clearly distinguishable and no areas of brighter contrast corresponding to carbon depletion and formation of tungsten (see Fig. 5) can be seen.

However, the tool microstructure beneath the worn surface shows signs of plastic deformation of individual WC grains and the network of WC grains (see highlighted examples in Fig. $7 \mathrm{~b}$ and c). Similar wear characteristics have been reported previously for turning of alloy 718 with the same tool grade [32].

\section{Discussion}

This study investigates the contribution of diffusion/ dissolution to the tool wear when machining alloy 718 and Waspaloy primarily by means of diffusion couple tests during which the intimate tool-workpiece contact in the cutting zone during machining is imitated.

It should be noted that the dynamic situation during cutting is different from the static conditions during the diffusion couple tests. For example, during cutting, a volume of workpiece material passes the tool rake or flank face in a fraction of a
Fig. 2 Cross-sectional SEM micrographs of the toolsuperalloy interfaces for the diffusion couples containing Alloy 718 (a, b) and Waspaloy (c, d) tested at the two temperatures. Note the parts of sample mounting resin in the upper part of $\mathbf{d}$ (a) Alloy $718-800^{\circ} \mathrm{C}$

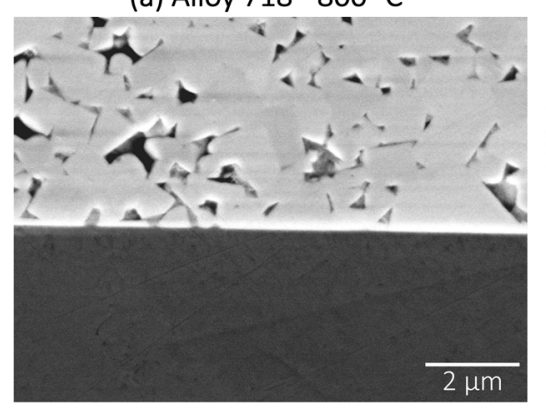

(c) Waspaloy $-800^{\circ} \mathrm{C}$

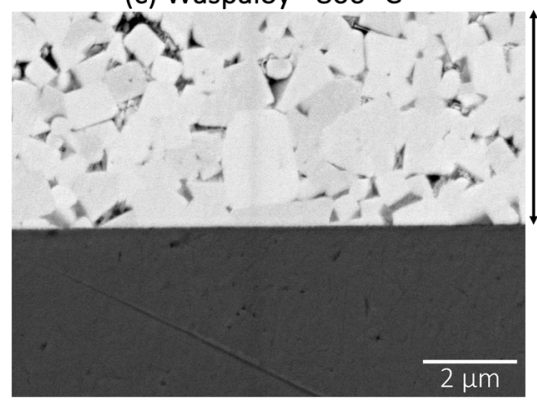

(b) Alloy $718-1000^{\circ} \mathrm{C}$

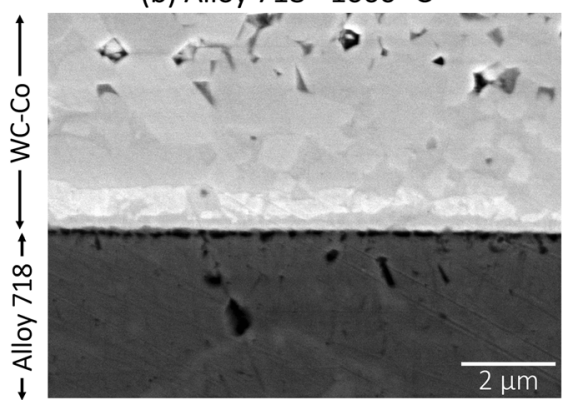

(d) Waspaloy $-1000^{\circ} \mathrm{C}$

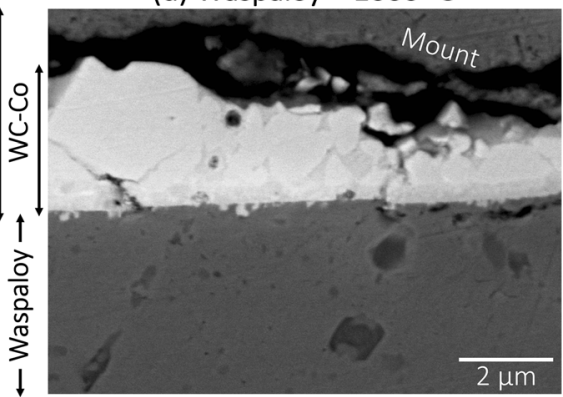


Fig. 3 Qualitative comparison of EDS line scans across the workpiece-tool interfaces after the four tests. Shown are normalized signals of $\mathrm{Ni}(\mathbf{a}, \mathbf{c})$ and $\mathrm{W}(\mathbf{b}, \mathbf{d})$
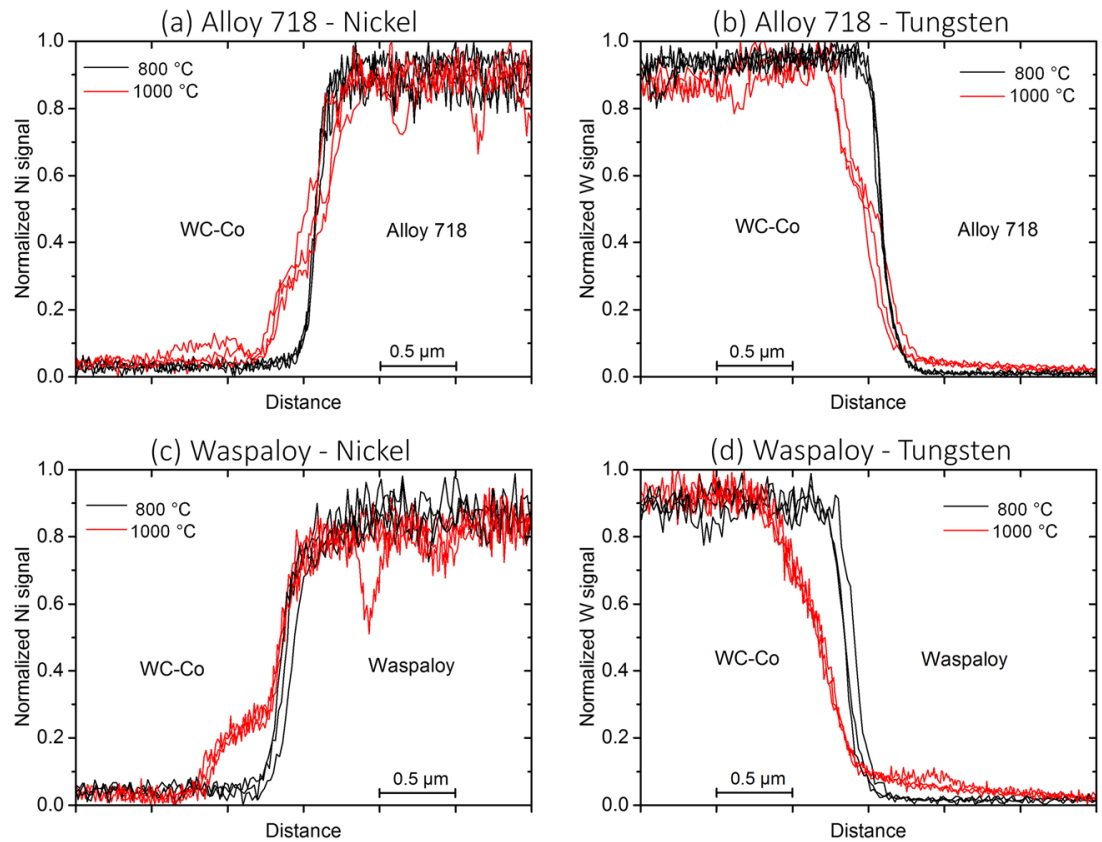

(d) Waspaloy - Tungsten

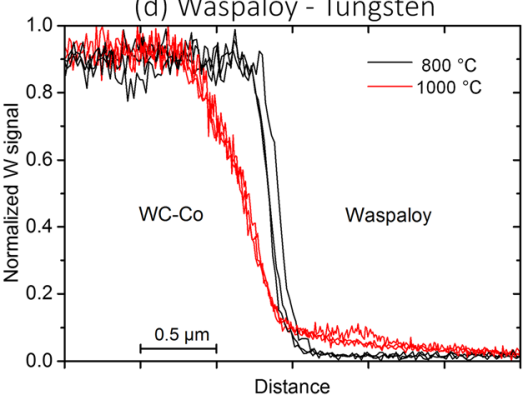

millisecond. This short contact time does not allow for significant diffusion of tool atoms into the workpiece material. Instead, dissociation of the tool material compound followed by atomic dissolution into a very narrow region of the chip/workpiece is the controlling mechanism [2, 3, 22]. It is therefore expected that for a given volume of the chip/workpiece adjacent to the interface with the tool, significantly less tool atoms dissolve and possibly diffuse into the superalloy in the cutting zone as compared with the diffusion couple tests. In a recent study, Saketi et al. [33] have applied the surface sensitive technique of time of flight secondary ion mass spectrometry to study the backside of stainless steel chips produced by turning using an uncoated cemented tungsten carbide tool. Their results show the presence of tungsten only in the range of a few tens of nanometers from the surface of the chip. However, since the used cutting speeds are in the range of tens of meters per minute, a significant amount of workpiece material slides across the tool surfaces on the rake and flank face. Therefore, even seemingly small amounts of tool atoms dissolving/diffusing into a given volume of the chip/workpiece could lead to a significant contribution of this wear mechanism to the overall tool wear.

Due to the described differences between the static situation during diffusion couple testing and the dynamic situation in the cutting zone, the diffusion couple results can only provide a qualitative comparison of the relative contribution to the wear when machining both alloys.

Tool wear by dissolution/diffusion is a thermally activated process and therefore said to increase in significance for increasing cutting temperatures. It is also considered to be mainly responsible for the crater wear on the tool rake side where the highest temperature occurs during cutting. However, it has also been shown that the interface temperature on the flank face increases significantly with increasing width of flank
Fig. 4 AES survey scans taken in close vicinity of the interface of the alloy 718 diffusion couple tested at $1000^{\circ} \mathrm{C}$. a SEM image with points of analysis. $\mathbf{b}$ Differentiated AES spectra with peak designations
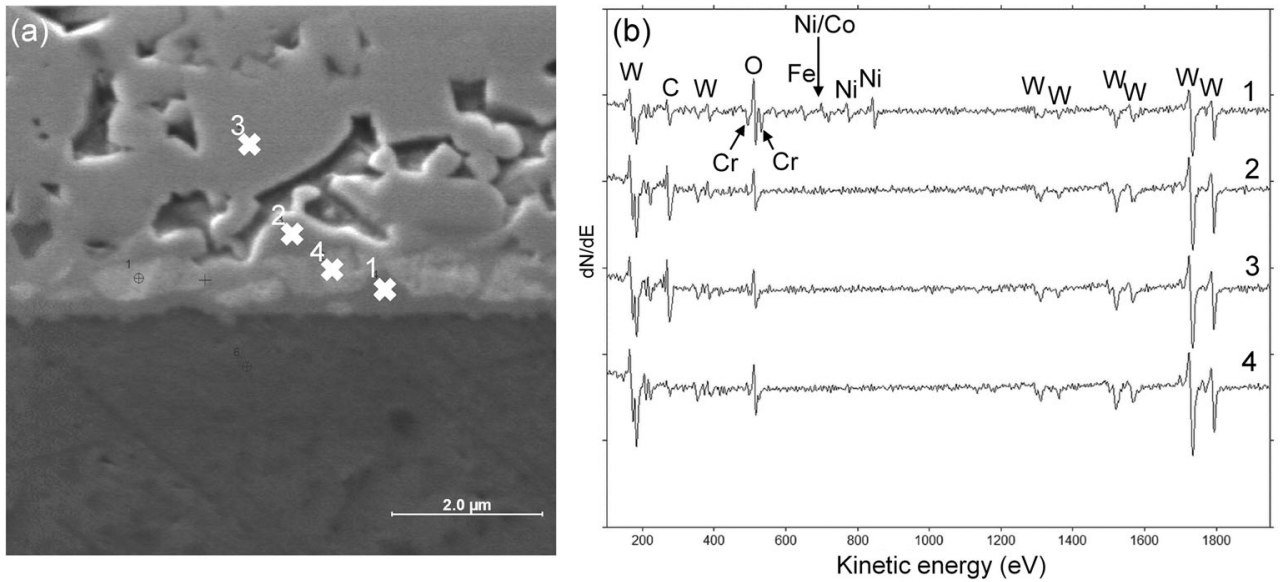
Fig. 5 Analysis of bright phase formed in diffusion couple containing alloy 718 . AES line scan showing peak intensities of tungsten and carbon across bright phase (a); part of binary tungstencarbon phase diagram (b); EBSD pattern obtained on bright phase (c) and with overlaid reference pattern of tungsten (d)

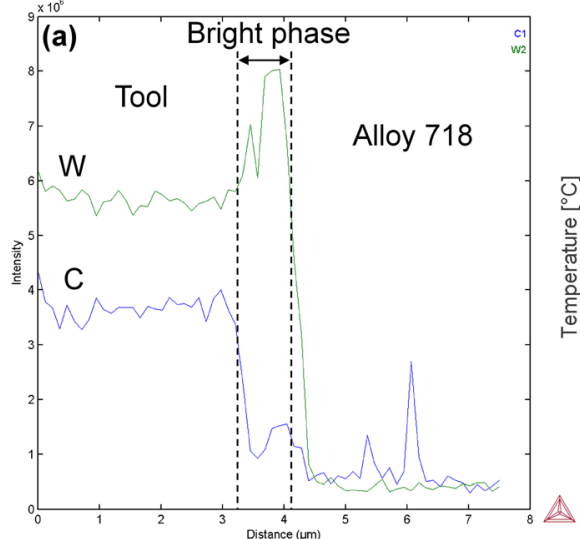

(b)
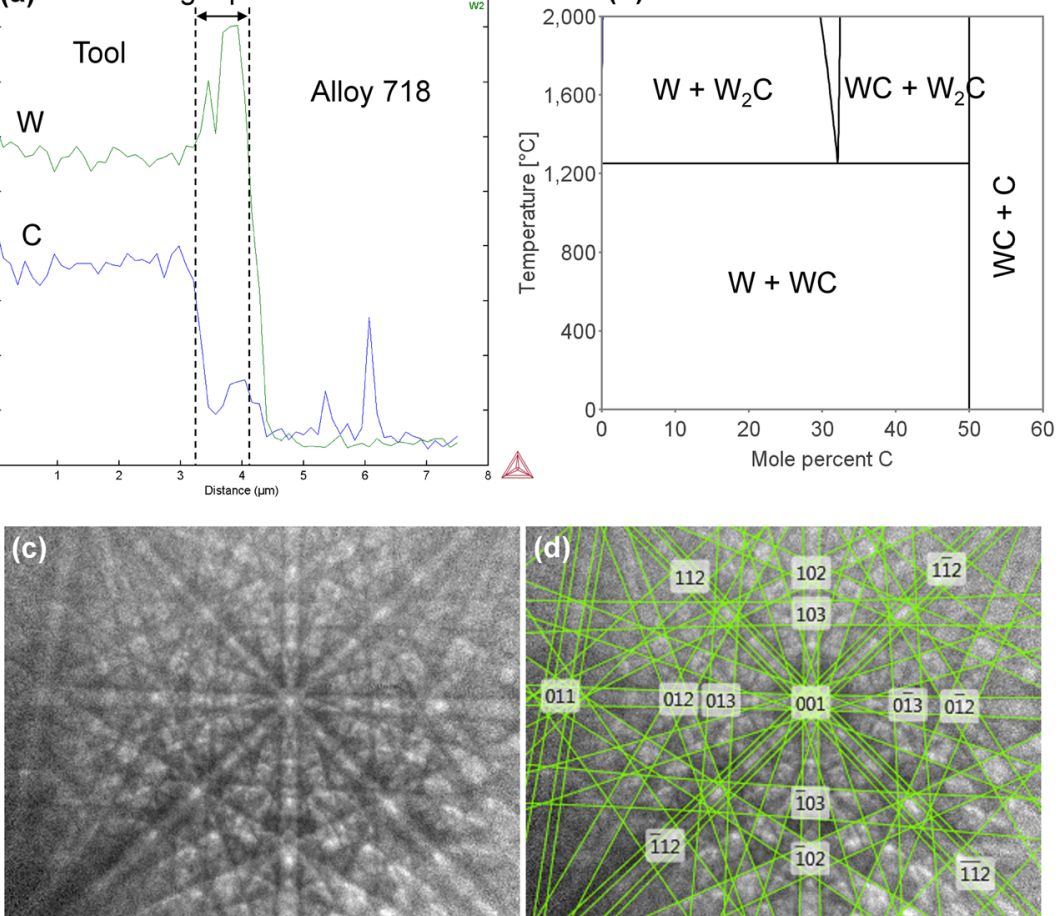

wear [4]. In that way, temperatures on the same order of magnitude as on the rake face could be reached and hence diffusion/dissolution wear could play an increasing role in the flank face of the cutting tool.

The static diffusion couple results are in agreement with the hypothesized increasing contribution of dissolution/diffusion for increasing cutting temperature. This is due to the observed increase in interdiffusion between superalloy and tool in both diffusion couples tested at the highest test temperature of $1000{ }^{\circ} \mathrm{C}$ which is shown in Fig. 3. The previously reported faster progression of flank wear when cutting alloy $718[13$, 15 ] is unlikely due to enhanced wear by diffusion/dissolution caused by higher temperatures in the cutting zone when machining this alloy as compared with Waspaloy. The reason is that when cutting the two superalloys using still unworn tools, a previous study concluded that similar temperatures are expected when the same cutting parameters are used [15].

For both alloy 718 and Waspaloy containing diffusion couples, presence of tungsten in the superalloys in close vicinity to the interface with the tool was shown by use of EDS. When comparing the diffusion couples of alloy 718 and Waspaloy tested at the same temperatures, no significant differences could be observed (see Fig. 3b and d). In both superalloys, a narrow region of roughly $1 \mu \mathrm{m}$ from the interface with the tool material showed slightly increased tungsten signal intensities. These results suggest that varying magnitudes of dissolution of tool atoms into the chip/workpiece are no major contributor to the differences in overall flank wear rates when machining
Fig. 6 Niobium-rich precipitates in alloy 718 in close vicinity to the diffusion interface after testing at $1000^{\circ} \mathrm{C}$. a SEM micrograph. b EDS map showing the distribution of niobium (a)

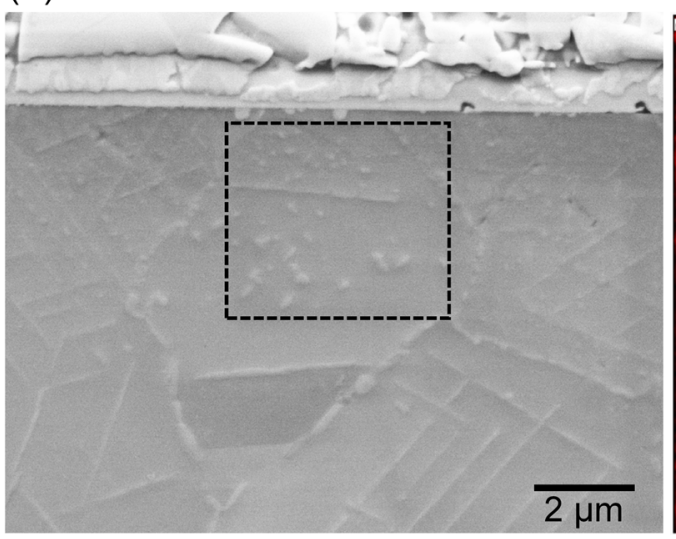

(b)

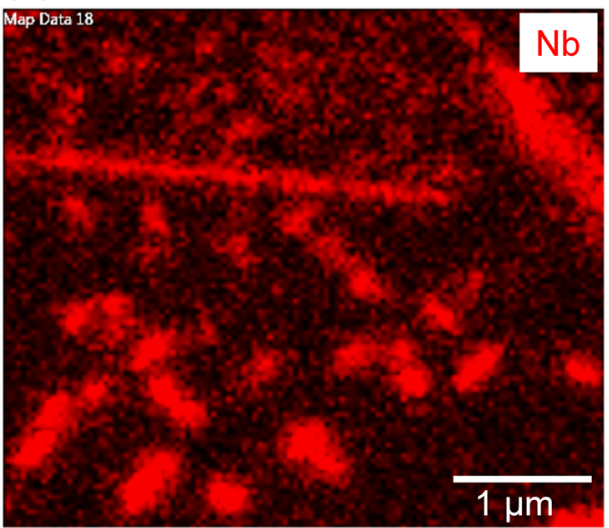


(a) Tool overview

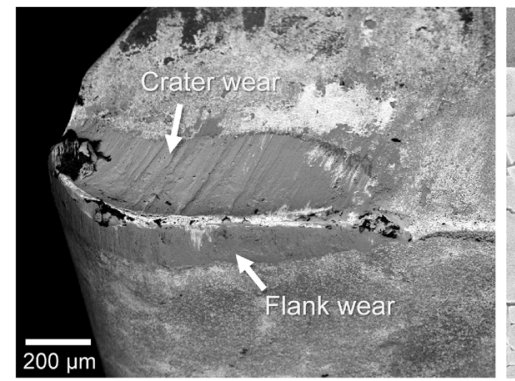

(b) Crater wear

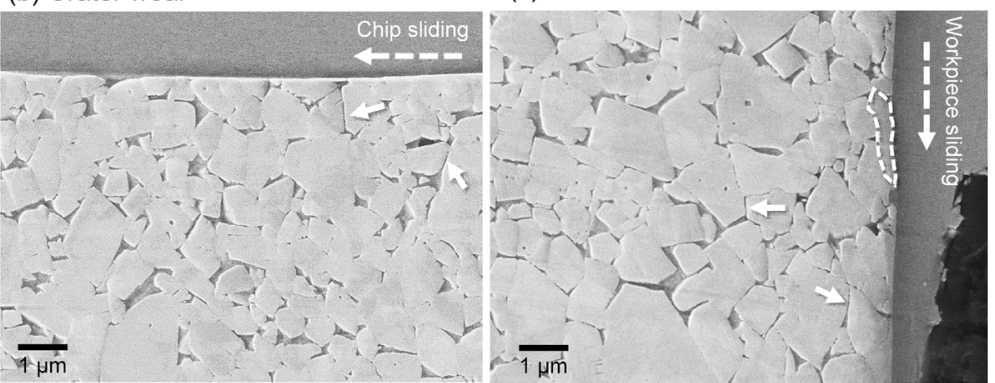

Fig. 7 Characteristics of tool wear after turning alloy 718. Overview micrograph showing the worn cutting edge $(\sim 230 \mu$ m maximum flank wear width) (a); cross-sectional view of tool microstructure beneath the crater (b) and the flank wear land (c). Arrows indicate signs of deformation of the WC network and a deformed/elongated WC grain is encircled the two alloys. This is also in agreement with the previous study where varying amounts of hard, abrasive carbides, and inclusions in the two machined superalloys were reported to be the main reason for the different flank wear rates [15].

It should however be highlighted that diffusion or dissolution process is nevertheless expected to have some contribution to the flank wear when machining both superalloys. The current state of flank wear during machining the respective superalloy dictates the interface temperature which in turn should affect the relative contribution of diffusion/ dissolution to the tool wear. Therefore, even though diffusion/dissolution wear is not expected to be the main reason for the difference in flank wear development, its relative contribution to the overall wear rate should in theory increase with progressively larger flank wear when machining alloy 718 as compared with Waspaloy.

Concerning the diffusion of workpiece atoms into the tool, it was observed that superalloy elements are present in a narrow region of the tool after the diffusion couple tests conducted at $1000{ }^{\circ} \mathrm{C}$ (see Figs. 3 and 4). Additionally, significant carbon depletion and formation of tungsten within the tool material were observed in the diffusion couple containing alloy 718 (see Figs. 2 and 5). In the corresponding Waspaloy containing diffusion couple, these phenomena were less pronounced and no significant carbon depletion and formation of tungsten were observable using the employed characterization techniques. A possible explanation for the different responses of the tool material during the diffusion couple tests is that the two superalloys contain different types and quantities of carbide forming elements. Of the present alloying elements, niobium has the strongest tendency to form carbides, followed by titanium [34]. Alloy 718 contains about $5.5 \mathrm{wt} \%$ niobium and about 0.9 wt\% titanium, whereas Waspaloy contains no niobium and about $3.1 \mathrm{wt} \%$ titanium (see Table 1). Due to its chemical composition, alloy 718 should therefore have higher affinity to carbon which could explain the observed carbon depletion of the tool material in close vicinity to the diffusion interface.

Elemental tungsten has significantly lower hardness as compared with WC, both at room temperature and at high temperature $[35,36]$. If tungsten forms during actual cutting of alloy 718 , it is therefore likely that the abrasion-resistance of the tool decreases locally which would lead to higher wear as compared with cutting of Waspaloy. However, no indications of formation of substantial amounts of tungsten were observed when characterizing the tool material just beneath the worn surfaces on the rake and flank face of the investigated worn tool (see Fig. 7). The lack of significant signs of carbon depletion and formation of tungsten during machining is likely connected to the fact that during machining, other tool wear mechanisms (e.g., abrasion) are active at the same time which can lead to immediate removal of the affected tool material. However, more detailed characterization using high resolution techniques is required to elaborate whether carbon depletion can contribute to the wear of cemented carbide cutting tools on a scale smaller than the resolution limit of SEM.

Based on the SEM examination in Fig. 7, it is likely that plastic deformation of the network of WC grains and of individual WC grains plays a role in addition to the previously reported abrasive wear mechanism [15] when cutting alloy 718 under the investigated conditions.

\section{Summary and conclusion}

In the present study, chemical interaction between uncoated WC-Co tools and alloy 718 and Waspaloy was investigated primarily by the use of static diffusion couples. The following key observations were made:

- Diffusion occurred from the tool material into both tested superalloys and vice versa, i.e., from the superalloys into the tool material. An increase in test temperature led to enhanced interdiffusion for both tested superalloys.

- No major difference in size of diffusion-affected zones adjacent to the tool/superalloy interfaces was observed when comparing both superalloys using the employed characterization technique. 
- The obtained results suggest that it is unlikely that the reported variations in flank wear rate when machining alloy 718 and Waspaloy are caused by significantly different magnitudes of tool atoms dissolving into the workpiece during cutting the two alloys.

- Depletion of carbon together with formation of tungsten within the tool in close vicinity to the interface with the superalloy was observed for the diffusion couple containing alloy 718 and tested at the highest temperature $\left(1000{ }^{\circ} \mathrm{C}\right)$. The possible role of these mechanisms in the tool wear process during the dynamic situation at the tool surface during cutting has to be investigated further. Preliminary examination by means of SEM suggests no significant contribution to the tool wear.

- The gained insights can find application for process optimization by physics-based models for tool wear prediction.

Acknowledgements Open access funding provided by Chalmers University of Technology.

Funding information This work is funded by Västra Götalandsregionen in association with the PROSAM project and additional support is provided by the Chalmers Area of Advance Production.

Open Access This article is licensed under a Creative Commons Attribution 4.0 International License, which permits use, sharing, adaptation, distribution and reproduction in any medium or format, as long as you give appropriate credit to the original author(s) and the source, provide a link to the Creative Commons licence, and indicate if changes were made. The images or other third party material in this article are included in the article's Creative Commons licence, unless indicated otherwise in a credit line to the material. If material is not included in the article's Creative Commons licence and your intended use is not permitted by statutory regulation or exceeds the permitted use, you will need to obtain permission directly from the copyright holder. To view a copy of this licence, visit http://creativecommons.org/licenses/by/4.0/.

\section{References}

1. Usui E, Shirakashi T, Kitagawa T (1984) Analytical prediction of cutting tool wear. Wear 100:129-151. https://doi.org/10.1016/ 0043-1648(84)90010-3

2. Kramer BM, Suh NP (1980) Tool wear by solution: a quantitative understanding. J Eng Ind 102:303-309. https://doi.org/10.1115/1. 3183869

3. Olortegui-Yume JA, Kwon PY (2007) Tool wear mechanisms in machining. Int J Mach Mach Mater 2:316-334

4. Malakizadi A, Gruber H, Sadik I, Nyborg L (2016) An FEM-based approach for tool wear estimation in machining. Wear 368-369:10 24. https://doi.org/10.1016/j.wear.2016.08.007

5. Wong T, Kim W, Kwon P (2004) Experimental support for a modelbased prediction of tool wear. Wear 257:790-798. Doi: https://doi. org/10.1016/j.wear.2004.03.010

6. Klocke F (2011) Manufacturing processes:1. https://doi.org/10. 1007/978-3-642-11979-8
7. Zhu D, Zhang X, Ding H (2013) Tool wear characteristics in machining of nickel-based superalloys. Int J Mach Tools Manuf 64: 60-77. https://doi.org/10.1016/j.ijmachtools.2012.08.001

8. Bouzakis K-D, Michailidis N, Skordaris G, et al (2012) Cutting with coated tools: coating technologies, characterization methods and performance optimization. CIRP Ann 61:703-723. Doi: https://doi.org/10.1016/j.cirp.2012.05.006

9. Grzesik W, Niesłony P, Habrat W et al (2018) Investigation of tool wear in the turning of Inconel 718 superalloy in terms of process performance and productivity enhancement. Tribol Int 118:337346. https://doi.org/10.1016/J.TRIBOINT.2017.10.005

10. Krook M, Recina V, Karlsson B (2005) Material properties affecting the machinability of inconel 718. Superalloys 718, 625, $706 \mathrm{Var}$ Deriv 613-627. doi: https://doi.org/10.7449/2005/Superalloys 2005_613_627

11. Cedergren S, Olovsjö S, Sjöberg G, Nyborg L (2013) The effects of grain size and feed rate on notch wear and burr formation in wrought alloy 718. Int J Adv Manuf Technol 67:1501-1507. https://doi.org/10.1007/s00170-012-4584-3

12. Olovsjö S, Hammersberg P, Avdovic P, Ståhl JE, Nyborg L (2012) Methodology for evaluating effects of material characteristics on machinability - theory and statistics-based modelling applied on alloy 718. Int J Adv Manuf Technol 59:55-66. https://doi.org/10. 1007/s00170-011-3503-3

13. Olovsjö S, Nyborg L (2012) Influence of microstructure on wear behaviour of uncoated WC tools in turning of alloy 718 and Waspaloy. Wear 282-283:12-21. https://doi.org/10.1016/j.wear. 2012.01.004

14. Polvorosa R, Suárez A, de Lacalle LNL et al (2017) Tool wear on nickel alloys with different coolant pressures: comparison of alloy 718 and Waspaloy. J Manuf Process 26:44-56. https://doi.org/10. 1016/j.jmapro.2017.01.012

15. Hoier P, Malakizadi A, Stuppa P et al (2018) Microstructural characteristics of alloy 718 and Waspaloy and their influence on flank wear during turning. Wear 400-401:184-193. https://doi.org/10. 1016/j.wear.2018.01.011

16. Wright PK, Trent EM (2000) Metal cutting, 4th edn. ButterworthHeinemann, Woburn

17. Jianxin D, Yousheng L, Wenlong S (2008) Diffusion wear in dry cutting of Ti-6Al-4V with WC/Co carbide tools. Wear 265:17761783. https://doi.org/10.1016/j.wear.2008.04.024

18. Jianxin D, Jiantou Z, Hui Z, Pei Y (2011) Wear mechanisms of cemented carbide tools in dry cutting of precipitation hardening semi-austenitic stainless steels. Wear 270:520-527. https://doi.org/ 10.1016/j.wear.2011.01.006

19. Naerheim Y, Trent EM (1977) Diffusion wear of cemented carbide tools when cutting steel at high speeds. 548-556

20. Gekonde HO, Subramanian SV (2002) Tribology of tool-chip interface and tool wear mechanisms. Surf Coatings Technol 149:151160. https://doi.org/10.1016/S0257-8972(01)01488-8

21. Liao YS, Shiue RH (1996) Carbide tool wear mechanism in turning inconel 718 superalloy. Wear 193:16-24

22. Wong T, Kim W, Kwon P (2004) Experimental support for a modelbased prediction of tool wear. Wear 257:790-798. https://doi.org/ 10.1016/j.wear.2004.03.010

23. Odelros S, Kaplan B, Kritikos M et al (2017) Experimental and theoretical study of the microscopic crater wear mechanism in titanium machining. Wear 376-377:115-124. https://doi.org/10.1016/ j.wear.2017.01.104

24. Hartung PD, Kramer BM, von Turkovich BF (1982) Tool wear in titanium machining. CIRP Ann - Manuf Technol 31:75-80. https:// doi.org/10.1016/S0007-8506(07)63272-7

25. Hatt O, Crawforth P, Jackson M (2017) On the mechanism of tool crater wear during titanium alloy machining. Wear 374-375:15-20. https://doi.org/10.1016/j.wear.2016.12.036 
26. Giménez S, Van der Biest O, Vleugels J (2007) The role of chemical wear in machining iron based materials by PCD and PCBN superhard tool materials. Diam Relat Mater 16:435-445. https://doi.org/ 10.1016/j.diamond.2006.08.017

27. Hatt O, Larsson H, Giuliani F et al (2016) Predicting chemical wear in machining titanium alloys via a novel low cost diffusion couple method. Procedia CIRP 45:219-222. https://doi.org/10.1016/j. procir.2016.01.196

28. Ramirez C, Idhil Ismail A, Gendarme C et al (2017) Understanding the diffusion wear mechanisms of WC-10\% Co carbide tools during dry machining of titanium alloys. Wear 390-391:61-70. https://doi. org/10.1016/J.WEAR.2017.07.003

29. von Fieandt L, M'Saoubi R, Schwind M, Kaplan B, Århammar C, Jansson B (2018) Chemical interactions between cemented carbide and difficult-to-machine materials by diffusion couple method and simulations. J Phase Equilibria Diffus 39:369-376. https://doi.org/ 10.1007/s11669-018-0639-y

30. Kwon P (2000) Predictive models for flank wear on coated inserts. Trans ASME: 122

31. Dastoor PC (2003) Auger electron spectroscopy and microscopy techniques and applications. In: Surf. Anal. Methods Mater. Sci. pp $155-171$
32. Hoier P, Klement U, Tamil N et al (2017) Flank wear characteristics of WC-Co tools when turning alloy 718 with high-pressure coolant supply. J Manuf Process 30:116-123. https://doi.org/10.1016/j. jmapro.2017.09.017

33. Saketi S, Bexell U, Östby J, Olsson M (2019) On the diffusion wear of cemented carbides in the turning of AISI $316 \mathrm{~L}$ stainless steel. Wear 430-431:202-213. https://doi.org/10.1016/j.wear.2019.05. 010

34. Davies J (1997) ASM speciality handbook: heat resistant materials. ASM International

35. Lassner E, Schubert W-D (1999) Tungsten: properties, chemistry, technology of the element, alloys, and chemical compounds. Kluwer Academic/Plenum Publishers

36. Miyoshi A, Hara A (1965) High temperature hardness of WC, TiC, $\mathrm{TaC}, \mathrm{NbC}$ and their mixed carbides. J Japan Soc Powder Metall 12: 78-84. https://doi.org/10.2497/jjspm. 12.78

Publisher's note Springer Nature remains neutral with regard to jurisdictional claims in published maps and institutional affiliations. 